\title{
A ordem pública do corpo humano e suas fronteiras legislativas no Brasil
}

\author{
Alexandre Zarias* (1)
}

\section{Resumo}

O objetivo deste artigo é examinar a ordem pública do corpo humano a partir de propostas legislativas a respeito da doação de sangue, doação de órgãos, gravidez por substituição, aborto e eutanásia. O corpo, como signo da relação dos seres humanos com o ambiente social, cultural e físico que os cerca, encerra um conjunto de representações da vida individual e coletiva, compondo uma gramática que se tornou objeto particular de uma sociologia especializada, constituída contemporaneamente e que já consolidou diferentes frentes de pesquisa. Assim, as discussões acerca do estatuto do corpo podem revelar a dimensão política que se dá a partir do enfrentamento entre diferentes concepções científicas e o senso comum a respeito do corpo em nossa sociedade. Trata-se de uma abordagem explicativa, de base documental, a partir da qual são analisados os conteúdos de projetos de lei que dizem respeito ao corpo. Esse material está disponível na Biblioteca Eletrônica da Câmara dos Deputados (Brasil), compreendendo o período legislativo de 1946 a 2019. O artigo mostra que é preciso analisar as fronteiras do corpo em relação à noção de pessoa e as variadas formas que essa relação assume em diferentes esferas do Direito.

Palavras-chave: corpo humano, aspectos sociais, Sociologia, Direito, Brasil.

\footnotetext{
• Este artigo deriva de uma comunicação que proferi no Instituto Universitário de Pesquisa Científica, da Universidade Mohammed V, na capital do Marrocos, Rabat, em 2 de maio de 2019. Registro meus agradecimentos ao sociólogo Abdelfattah Ezzine, daquela universidade, por seus comentários. Também sou grato ao sociólogo David Le Breton por seu apoio durante minha pesquisa pós-doutoral, na Universidade de Estrasburgo (Unistra), França, ocasião em que reuni, entre 2018 e 2019, os dados aqui analisados. As pesquisadoras Virginie Le Corre e Eliane Eock da Unistra igualmente contribuíram com sugestões e críticas ao texto original que culminou nesta versão.

*Fundação Joaquim Nabuco, Recife, PE, Brasil.
} 


\section{The public status of human body and its legislative boundaries in Brazil}

\section{Abstract}

The purpose of this article is to examine the public status of the human body by analyzing legislative bills involving blood donation, organ donation, surrogacy, abortion and euthanasia. The body, as a sign of the relation of human beings to the social, cultural and physical environment surrounding them, encloses a set of representations of individual and collective life, composing a grammar that became a particular object of a specialized corpus within sociology. Discussions about the body statute can reveal the political dimension emerging from the encounter between different scientific conceptions and the conventional wisdom about the body in our society. This explanatory research, based on documental analysis, focused on the contents of legislative bills involving human body. The legislative corpus is available at the Brazilian Electronic Library of the Chamber of Deputies, and comprehends the period from 1946 to 2019 . The article shows that it is necessary to analyze the boundaries of the body in relation to the notion of person and the various forms taken by this relation in different spheres of the Law.

Keywords: human body, social aspects, Sociology, Law, Brazil.

[...] nunca houve ser humano que não tenha tido o senso, não apenas do seu corpo, mas também de sua individualidade espiritual e corporal ao mesmo tempo.

(Marcel Mauss, Uma categoria do Espírito Humano: a noção de pessoa, a de "Eu" [1938], 2003, p. 371).

\section{Prólogo: a (des)personificação do corpo condenado}

\footnotetext{
$\mathrm{R}$ io de Janeiro, 21 de abril de 1792. O alferes José Joaquim da Silva Xavier, o conhecido Tiradentes, é condenado à morte por crime a libertar da Coroa Portuguesa a Capitania de Minas. O mandado de execução de sua pena estabelece que
} 
[...] com baraço e pregão, seja levado pelas ruas públicas desta cidade ao lugar da forca, e nela morra morte natural para sempre, e que separada a cabeça do corpo seja levada a Vila Rica, onde será conservada em poste alto junto ao lugar da sua habitação, até que o tempo a consuma; que seu corpo seja dividido em quartos, e pregados em iguais postes pela entrada de Minas, nos lugares mais públicos, principalmente no da Varginha e Cebolas; que a casa da sua habitação seja arrasada e salgada, e no meio de suas ruínas levantado um padrão em que se conserve para a posteridade a memória de tão abominável réu e delito, e ficando infame para seus filhos e netos, Ihe sejam confiscados seus bens para a Coroa e Câmara Real (Autos de devassa, 1982, p. 282).

Quase duzentos anos após a morte de Tiradentes, encontramos proposições legislativas contemporâneas que fazem do corpo objeto de punição, porém de maneira diversa. Em 1991, o deputado federal Francisco Silva (PDC-RJ) propôs uma lei nos seguintes termos (Projeto de Lei $1471 / 1991)^{1}$ :

O Congresso Nacional decreta:

Art. 1ํ - Será compulsória a doação de órgãos, tais como coração, pulmões, rins, olhos e outros, por criminosos condenados pelos crimes capitulados no XLIII do Art. 5o da Constituição Federal e Artigos 121, 127, 213 e §3음o Artigo 129 do Decreto-Lei de 07 de dezembro de 1940 (Código Penal).

Art. $2^{\circ}$ - A doação será feita em vida pelos apenados, desde que as sentenças condenatórias tenham transitado em julgado (Brasil, 1991b).

Entre a condenação de Tiradentes e a proposta legislativa de Francisco Silva, somos confrontados com soluções paradoxais. Na primeira, a pena de morte e a danação do corpo são consideradas como uma condenação da pessoa para além de sua existência física. Na segunda, a pessoa, em sua existência carnal, é condenada pela retirada de uma parte de seu corpo enquanto viva. A distância histórica que separa um caso do outro exemplifica o caráter mutável e fluído do estatuto legal do corpo, o qual encontra uma de suas principais fronteiras quando confrontado com a noção de pessoa.

O Tiradentes esquartejado, no famoso óleo sobre tela de Pedro Américo, de 1893, imagem quase obrigatória nos livros didáticos de História, lembra

${ }^{1}$ Os crimes elencados na proposta são: tortura, tráfico ilícito de entorpecentes e drogas afins, terrorismo, crimes hediondos, lesão corporal seguida de morte, homicídio, aborto e estupro. 
um corpo transcendente de inspiração cristã que evocamos para compor a imagem nacional de independência. Integra o que Carvalho (1995) chamou de "domínio do mito", isto é, o imaginário manifestado artística e ritualmente. O tipo de condenação imposto ao mártir nacional, com base nas Ordenações Filipinas, cuja parte penal e processual penal foi revogada pelos códigos criminal e de processo criminal do Império, em 1830 e 1832, respectivamente, ressoa em propostas legais atuais, tais como a do deputado Francisco Silva reproduzida acima, a qual serviu de inspiração para outras de doação compulsória de órgãos tratadas mais adiante: os projetos de lei números 3857/2004, 727/2019 e 729/2019. Proposições dessa natureza, confrontadas com as Ordenações, exemplificam como corpo e pessoa ora são idênticos, ora são considerados objetos particulares.

Nos países de tradição latina, a identidade entre corpo e pessoa tem suas raízes no Direito romano que não fazia nenhuma distinção entre uma noção e outra. Contudo, o estatuto jurídico do corpo modificou-se ao longo do tempo, de maneira que ele já não é imediatamente identificado com a pessoa. Os laços que os unem e a distância que os separa são desafios não somente para o Direito, mas também para uma Sociologia interessada no lugar do corpo nas sociedades ocidentais.

\section{O corpo: nem ponto de partida, nem ponto de chegada}

Meu interesse neste artigo é tratar da ordem pública do corpo, utilizando como referência o processo legislativo brasileiro, isto é, o estágio que precede a criação de uma lei. Pode-se dizer que a ordem pública do corpo exprime um conjunto de crenças, valores morais e conhecimentos científicos que são transformados em lei e, por consequência, produzem seus efeitos, orientando as ações das pessoas e suas relações sociais sobre tudo o que diz respeito à sua existência carnal.

Tal como indicado por Le Breton (2015), o corpo não é um resposta, mas sim uma questão. Meu objetivo é, portanto, o de mostrar como é possível declinar essa questão de diferentes maneiras, para compreender um pouco mais acerca do estatuto do corpo a partir de exemplos tirados do processo legislativo brasileiro. O sociólogo francês associa aos esforços anatômicos dos séculos XVI e XVII uma transformação do estatuto humano segundo 
o qual corpo e alma, ou corpo e mente, são dissociados. A publicação, em 1543, de De Humani Corporis Fabrica², clássico manual de anatomia de Andreas Vesalius, e a máxima "penso, logo existo", de Descartes, em seu Discurso sobre o método, de 1637, são sinais históricos dessa ruptura epistemológica que inaugura o dualismo que separa corpo e pessoa nos ordenamentos jurídicos ocidentais de origem latina.

O Direito, evidentemente, acompanhou de perto a dialética entre corpo e pessoa, colocando em perspectiva o estatuto jurídico do corpo do condenado em favor de uma causa científica e médica, baseada no estudo de cadáveres (Le Breton, 1993). De uma parte, o condenado rompe o laço social e merece ser condenado. Porém, de outra parte, trata-se de uma condenação que abre a oportunidade transcendental de o condenado suplantar o mal cometido e, ao mesmo tempo, dá uma autorização terrena para dissecar seus despojos, ou seja, uma oportunidade de progresso científico e de ampliação dos conhecimentos médicos como meio de pagar os erros cometidos em vida.

As ambiguidades em relação ao corpo e sua identificação com a noção de pessoa são presentes nos debates legislativos sobre a doação de sangue e órgãos, gravidez por substituição, aborto, eutanásia — assuntos esses tratados mais adiante e que servem de exemplos para a discussão aqui empreendida —, pesquisa com embriões humanos, redesignação sexual etc. Segundo Edelman (2009, p. 8), o Direito tem um valor genealógico, trata-se da última instância - aquela que torna inteligíveis as discussões acerca do corpo e suas transformações sociais, ao estabelecer o que é legítimo ou ilegítimo, lícito ou ilícito, permitido ou proibido - "que produz uma continuidade", por meio de normas, ao "integrar o novo ao antigo".

As respostas dadas pela lei são diversas. Cada país tem suas próprias regras. O aborto, tomando como exemplo um caso sul-americano, é permitido no Uruguai até a décima segunda semana de gestação. No Brasil, entretanto, é permitido apenas em certos contextos, quando a

${ }^{2}$ Tratado médico anatômico composto originalmente por sete livros contendo 700 páginas e 300 gravuras de corpos dissecados. Segundo Le Breton (1993, p. 74, tradução minha), "Vesalius inaugura uma outra abordagem do corpo humano, plena de consequências. Simbolicamente, uma fratura é alcançada, a qual dissocia o homem de sua carne para fazer do cadáver o equivalente moral de um resto". 
gravidez resulta de estupro, ou tal como o previsto pela figura do "aborto necessário", isto é, quando a mulher corre risco de vida por conta de sua gestação. Além disso, o estatuto do corpo não é exatamente idêntico numa mesma ordem legal. Se o código penal brasileiro de 1940 já consagrou a punição ao aborto, o Supremo Tribunal Federal (STF), por sua vez, acumula decisões polêmicas a esse respeito, fazendo distinção entre as noções de "aborto", "antecipação terapêutica do parto" e "interrupção da gravidez".

Em 12 de abril de 2012, o STF julgou procedente a Arguição de Descumprimento de Preceito Fundamental (ADPF) número 54, autorizando mulheres grávidas de fetos anencéfalos a interromperem a gravidez. Salientese que o relator do processo, Ministro Marco Aurélio, enfatiza que: "mostrase inteiramente despropositado veicular que o Supremo examinará, neste caso, a descriminalização do aborto, especialmente porque, consoante se observará, existe distinção entre aborto e antecipação terapêutica do parto" (Brasil, 2012). Mas, em decisão de 29 de novembro de 2016, o STF proferiu decisão descriminalizando o aborto até a décima segunda semana de gestação, por meio do voto do ministro Luís Roberto Barroso, no julgamento do Habeas corpus número 124.306, que tratava da soltura de réus presos preventivamente acusados de praticá-lo ${ }^{3}$. Atualmente, o problema é pauta das discussões sobre o "aborto necessário", presente na Ação Direita de Inconstitucionalidade (ADI) número 5581, de 24 de agosto de 2016, a qual aguarda julgamento e trata da interrupção da gravidez nos casos de fetos com microcefalia decorrente da contaminação de gestantes pelo Zika vírus (Brasil, 2016a).

${ }^{3}$ Em sua decisão, lê-se: "[...] é preciso conferir interpretação conforme a Constituição aos próprios arts. 124 a 126 do Código Penal - que tipificam o crime de aborto - para excluir do seu âmbito de incidência a interrupção voluntária da gestação efetivada no primeiro trimestre. A criminalização, nessa hipótese, viola diversos direitos fundamentais da mulher, bem como o princípio da proporcionalidade [...] A criminalização é incompatível com os seguintes direitos fundamentais: os direitos sexuais e reprodutivos da mulher, que não pode ser obrigada pelo Estado a manter uma gestação indesejada; a autonomia da mulher, que deve conservar o direito de fazer suas escolhas existenciais; a integridade física e psíquica da gestante, que é quem sofre, no seu corpo e no seu psiquismo, os efeitos da gravidez; e a igualdade da mulher, já que homens não engravidam e, portanto, a equiparação plena de gênero depende de se respeitar a vontade da mulher nessa matéria" (Brasil, 2016b). 
Enfim, no que concerne ao corpo, as leis são respostas provisórias. Nos bastidores de sua criação, há debates fervorosos que se estendem por décadas. Pelo fato de cada debate legislativo ter seu contexto, para compreendê-lo é preciso examinar de que forma são construídas as fronteiras entre o corpo e a pessoa. Elas são inumeráveis e podem ser demarcadas segundo o estatuto do corpo antes do nascimento e após a morte, nos limites entre o Direito Civil e o Penal, entre os direitos das pessoas e a lei das coisas, nos princípios de dignidade e individualidade ou de autonomia, responsabilidade, entre humano e desumano, naquilo que separa a natureza da cultura.

\section{Entre corpo e pessoa: breve percurso teórico}

Dentro dos limites deste artigo, selecionei deliberadamente a literatura francesa que permite desenvolver uma reflexão a respeito da ordem pública do corpo. Não se trata de uma revisão exaustiva, mas sim de uma escolha pontual que desenha o panorama sobre o qual é possível localizar o objeto em análise e organizar um programa de pesquisa. Além dos trabalhos de Marcel Mauss ([1934] 2003a; [1938] 2003b) e de David Le Breton (1992; 1993 ; 1998; 2017) recorrentemente citados, os quais firmam as bases da exposição geral sobre o tema em discussão, sirvo-me também de Labbée (1990), Baud (1993), Chauvenett (2005) e Edelman (2009), que tratam especificamente do estatuto do corpo humano na ordem jurídica.

Na segunda metade dos anos de 1930, Marcel Mauss (2003a; 2003b) trouxe a público dois trabalhos que se tornaram clássicos da sociologia e da antropologia, leituras obrigatórias para estudantes e profissionais das duas áreas: As técnicas do corpo, de 1934, e Uma categoria do espírito humano: a noção de pessoa, a de 'Eu', de 1938. Na primeira obra, Mauss interessa-se pela forma tradicional em que os homens "sabem servir-se de seu corpo" (2003a, p. 401). É nela que nos deparamos com o conceito de habitus, herdado de seu tio Émile Durkheim, e posteriormente desenvolvido por Pierre Bourdieu sob nova ótica, cujo sentido latino original refere-se ao "adquiro" e à "faculdade" do espírito moldados pela vida em sociedade, "educações, conveniências e modas, prestígios" (Mauss, 2003a, p. 404). O interesse de Mauss está circunscrito à técnica e não ao sentido que o corpo, 
tal como categoria, assume em diferentes sociedades. Na segunda obra, diferentemente, Mauss toma "pessoa" como categoria do espírito humano, e faz de sua curiosidade uma "pesquisa de direito e moral", a partir da análise de "direitos, religiões, costumes, estruturas sociais e mentalidades" (Mauss, 2003b, p. 371). Enfim, uma história social da noção de pessoa, num longo percurso que começa pela figura da personagem entre os Zuñi do México, até a pessoa, no seu sentido psicológico hodierno de "Eu".

Segundo Mauss, a noção de pessoa latina está ligada à máscara ritual: per (por onde) sonna (soa), por onde soa a voz do ator, aquele que encarna a vida de outrem. Em direito romano, a pessoa é um "fato fundamental de direito" que delimita sua natureza em relação às res, coisas, e às actiones, ações, tornando-se "sinônimo da verdadeira natureza do indivíduo" (Mauss, 2003b, p. 385-389). O escravo, sublinha o autor, não tem direito à personalidade e aqui interessa uma restrição fundamental, pois ele não pode ser proprietário de seu corpo, não possui ascendentes nem nome, sobrenome e muito menos bens. O sentido clássico de pessoa deriva da soma de seu significado jurídico primevo com um sentido moral, de ser autoconsciente, livre e responsável (Mauss, 2003b). Ao longo da história, ganhou contornos metafísicos a partir do cristianismo, identificada como substância racional, indivisível e individual, alcançando seu sentido moderno, de ser psicológico, identificado com o "Eu", que é expresso pela summa divisio cartesiana, aquela que separou o corpo da mente, opondo-o ao pensamento. Conforme frisado acima, fato histórico que consolida as empreitadas anatomistas do século XVI que fizeram do corpo um invólucro despersonalizado, abrindo novas fronteiras no Direito.

A pessoa, em carne e osso, no Direito, é chamada de "pessoa física" ou "pessoa natural" (Silva, 2005, p. 1039). Para além do seu sentido encarnado, que expressa o lugar do ser humano no mundo, a noção de pessoa também pode dizer respeito a entidades personalizadas, tais como as "pessoas jurídicas", "pessoas coletivas" ou "pessoas morais". O indivíduo autônomo, moral, racional e responsável por seu destino conforma o direito liberal ocidental fundado na dicotomia pessoa-corpo. Segundo Pereira (1994), o sujeito destinatário da norma jurídica tem o poder sobre a própria pessoa ou sobre o próprio corpo, porém nas fronteiras de sua integridade física: 
O direito ao próprio corpo é um complemento do poder sobre si mesmo, mas só pode ser exercido no limite da manutenção da sua integridade. Todo ato que implique atentado contra esta integridade é repelido por injurídico. Daí a legitimidade da repressão ao uso de estupefacientes, a iliceidade [sic] dos atos que possam importar em mutilação etc. Não pode ter valor o contrato de venda de um dedo sequer. Mas é válido o negócio jurídico, que tenha por objeto a alienação de uma parte do corpo suscetível de regeneração, como a venda de cabelos, ou a doação de sangue. Pode igualmente o indivíduo dispor de seu cadáver, determinando o seu destino, como no caso de sua utilização para estudos anatômicos, ou a retirada de uma parte dele para fins humanitários, com a extração da córnea para ser usada em um cego (Pereira,1994, p. 25).

Chauvenett (2005) vai além dessa noção da integridade, revelando mais um dos limites da separação corpo-pessoa em oposição aos bens, às coisas e ao papel do Estado:

na ausência de um bem material que defina a autonomia concreta da pessoa pelo bom e mau uso que ela faz dessa autonomia dentro de um quadro de direito concreto (o direito civil), a tutela direta do Estado se exerce considerando que o indivíduo disponha de seu corpo para exercer a liberdade. Dispondo de bens, os sujeitos podem trocá-los entre si, por contrato, sem intervenção do Estado (ou então tê-lo como terceiro fiador e simbólico) e engajar aí sua responsabilidade. Os outros sujeitos só têm sua moral e seu corpo para engajar, seja no quadro do Direito Penal, como o vagabundo, seja no quadro do Direito Social mais amplo (Chauvenett, 2005, p. 36-37).

Assim, o corpo como extensão do poder sobre si mesmo, princípio fundado na integridade do indivíduo, normatiza uma série de relações e também o "sentido coletivo da vida em sociedade" (Chauvenett, 2005, p. 54). O corpo, por assim dizer, tem limites. Não é apenas o limite físico que, nas palavras de Le Breton (1992, p. 10), "é a marca do indivíduo, a fronteira que, de alguma forma, o distingue dos outros". Esses processos de distinção fundados no corpo, por assim dizer, são históricos, contingentes e fluidos. Eles fixam a extensão da vida em sociedade que, em parte, é regulada pelo Direito, o qual também normatiza os usos do corpo por meio da noção de responsabilidade: 
Com a responsabilidade, a pessoa e o corpo mudaram de status jurídico. As máquinas vivas tornam-se mais concessões duráveis, cujo título é protegido pelo poder público, do que bens [...]. O corpo, bem material por excelência, separa-se da pessoa para se tomar um atributo. É o que sublinha David (1973, p. 11): "O ano 1967, ano do primeiro transplante de coração, foi sem dúvida uma data importante: a da separação com o corpo". O corpo não pertence mais à pessoa: a pessoa não é um corpo, ela tem um corpo, dado a ela, intercambiável e uma riqueza, que pode ser dada e transplantada, é simulável e se torna uma vestimenta preciosa, porém anônima (Chauvenett, 2005, p. 39).

Ao que Chauvenett (2005) diz acima em relação ao transplante de coração, acrescentem-se outros avanços da medicina do Pós-guerra, que modificaram ainda mais o estatuto do corpo humano. A doação de sangue e a criação de bancos para o seu armazenamento, a fertilização in vitro, a manipulação do DNA, a possibilidade de fazer reviver corpos congelados, a inteligência artificial etc. fazem do corpo um simulacro, matéria provisória e morada passageira da pessoa que pode modificá-lo quando e como bem entender, fazendo dele apenas um molde descartável - o que Mauss (2003b) chamou de "culto ao Eu", sua aberração, em oposição ao "respeito ao Eu", em particular, ao dos outros, sua norma.

Para aprofundar ainda mais as questões acerca desse assunto, o jurista Xavier Labbée (1990), de quem empresto a expressão "ordem pública do corpo humano", indaga-se a respeito da condição jurídica do corpo antes do nascimento e depois da morte. Sua análise é complexa, pois confronta todas as possibilidades de classificação do corpo no Direito Civil e Penal francês. Neste artigo, destaco somente sua argumentação inicial, que trata das fronteiras da vida, delimitadas por três fatos jurídicos concretos expressos pelas noções de concepção, viabilidade e morte. Em primeiro lugar, o Código Civil francês - e o brasileiro é semelhante - não define o momento da concepção, apenas a presume dentro de um certo período para estabelecer a filiação ${ }^{4}$. Atualmente, a indeterminação jurídica

${ }^{4}$ De acordo com o art. 1.597 do Código Civil de 2002, "[p]resumem-se concebidos na constância do casamento os filhos: I - nascidos cento e oitenta dias, pelo menos, depois de estabelecida a convivência conjugal; II - nascidos nos trezentos dias subsequentes à dissolução da sociedade conjugal, por morte, separação judicial, nulidade e anulação do casamento" (Brasil, 2004). A lei brasileira também prevê a fixação da filiação nos casos de inseminação artificial homóloga e heteróloga, mesmo quando depois da morte do marido. 
acerca do momento da concepção e o estatuto do embrião, que não tem personalidade jurídica, ou seja, não é pessoa, delimitam a arena na qual se defrontam as correntes contra e a favor do aborto ${ }^{5}$. Em segundo lugar, não basta haver um embrião formado, é preciso que este seja viável, noção também fugidia, para a qual o Direito não oferece solução clara. No caso francês, a viabilidade presume a "maturidade" e a "boa conformação" como qualidades indeterminadas que permitem a vida de um ser fora do útero materno. No caso brasileiro, por exemplo, podemos remeter a discussão para a possibilidade de interrupção da gravidez no caso de fetos anencéfalos, cujas mães contraíram o Zika vírus durante a gestação, caso em julgamento pelo STF, como já mencionado acima. Em terceiro lugar, com a morte, cessa a personalidade jurídica ${ }^{6}$. Mas como determiná-la? Segundo Labbée (1990), a condição jurídica do cadáver é diferente da condição jurídica do corpo da pessoa viva. A medicina recria a todo o tempo a "viabilidade" do ser vivente, mas doente, desenvolvendo meios de manutenção das funções orgânicas. É nesse campo que começam as discussões acerca da eutanásia. Enfim, destaca o autor, o Direito não define o que é concepção, tampouco viabilidade ou morte. Apenas acompanha os critérios da Medicina e da ciência em contextos históricos determinados.

Se determinar os limites da vida e da morte oferece desafios para pensarmos a relação corpo-pessoa no Direito, o que dizer do organismo em partes, destacadas ou fixadas ao conjunto? Jean-Pierre Baud (1993) inicia uma interessante reflexão a esse respeito em "O caso da mão roubada" (em tradução livre do original, L'affair de la main volée) para tratar do estatuto do corpo em relação à noção de pessoa, bens e coisas. A história resumida é a seguinte: um homem, em trabalho de jardinagem, decepa uma de suas mãos, deixa o local e abandona o membro amputado; seu

\footnotetext{
${ }^{5}$ Apesar disso, a lei assegura direitos ao nascituro, ainda que indeterminados. Segundo o Código Civil, art. 20, "[a] personalidade civil da pessoa começa do nascimento com vida; mas a lei põe a salvo, desde a concepção, os direitos do nascituro" (Brasil, 2004).

${ }^{6}$ De acordo com o Código Civil brasileiro de 2002, art. 6o, "[a] existência da pessoa natural termina com a morte; presume-se esta, quanto aos ausentes, nos casos em que a lei autoriza a abertura de sucessão definitiva" (Brasil, 2004).
} 
vizinho, mal-intencionado, toma-a, jogando-a num incinerador utilizado para aquecimento residencial. Segundo Baud, o direito francês poderia oferecer três soluções. Numa delas, o vizinho é condenado por mutilação, segundo a parte do Código Penal que trata do crime contra as pessoas. Noutro cenário, o vizinho é condenado por roubo, pois a mão, por não fazer mais parte do corpo, inscreve-se na categoria das coisas e, embora já não faça parte da pessoa, lhe pertence. A última solução é a absolvição, pois o membro amputado, abandonado no local, já não faz mais parte de quem o detinha antes do acidente. Assim, encontrado por outrem, trata-se de uma mão sem dono. Portanto, tomá-la para si, de forma não fraudulenta, descaracteriza o roubo. Essas três saídas, segundo Baud (1993, p. 16, tradução minha), seriam consequências do "princípio segundo o qual a dignidade humana proíbe que se reconheça ao homem um direito de propriedade sobre seu próprio corpo". A consequência desse princípio é que qualquer parte destacada do corpo assume um estatuto incerto. $\mathrm{O}$ sangue, por exemplo, já foi comercializado no Brasil. Atualmente, não tem status de mercadoria. Vendem-se cabelos, mas os órgãos humanos não são comercializáveis. Na Roma Antiga, a urina era taxada, pois servia como matéria-prima para a lavagem de roupas, entre outras coisas. O DNA, segundo Edelman (2009), tornou-se objeto de patente industrial.

A vida, enfim, na sua expressão maior que é o corpo, entrou no terreno da manipulação, o qual pode ser esquadrinhado por meio das transformações pelas quais passa o Direito. Neste texto, exponho e proponho uma das formas de compreender essas mudanças, que é por meio do estudo das propostas legislativas. Antes de passar à análise, vejamos o que dizem as leis brasileiras sobre o assunto.

\section{Algumas notas sobre o corpo no sistema legal brasileiro}

O Brasil possui um sistema legal genérico para a proteção da integridade física do corpo e reparação por lesões corporais, conforme definido em sua Constituição Federal, Código Civil, Código Penal, leis complementares e ordinárias, bem como atos infralegais, acordos e tratados internacionais 
de que o país é signatário ${ }^{7}$. Esses princípios são: 1) dignidade da pessoa humana; 2) inviolabilidade do corpo; 3) autonomia e consentimento; e 4) não patrimonialidade. Não há definição legal do corpo na legislação brasileira. O que existe é a clássica divisão romana do Direito entre a proteção da pessoa e a proteção dos bens, na qual o corpo, embora identificado com a primeira, por razões históricas, ultrapassa essa linha em direção aos outros. Mas essa oscilação tem seus limites marcados por alguns princípios adicionais de proteção, que são: 1) indisponibilidade; e 2) caráter fora do comércio (Brauner; Lobato, 2015).

O corpo não é uma mercadoria segundo a lei brasileira. Não se pode vender parte do corpo ou todo o corpo. Mas é possível doá-lo, em todo ou parte, por livre escolha e consentimento. Pode-se doar um rim, sangue, esperma, óvulos, pele, parte do fígado, ser mãe substituta, legar a um laboratório de anatomia o próprio cadáver, desde que haja consentimento e que tais atos não causem prejuízo a si mesmo ou a outrem.

Historicamente, o Legislativo brasileiro acumula um grande número de projetos de lei relacionados com o corpo. Pode-se dizer que se trata de abordagens específicas, de um corpo fatiado, que não é concebido na sua totalidade. Portanto, temos propostas de doação e uso de partes do corpo, de seus fluidos e produtos, acerca dos limites da vida e da morte, ou seja, se podemos ou não fazer o aborto e a eutanásia, da fertilização medicamente assistida etc. Apesar do acúmulo de propostas e debates legislativos, parte das decisões relativas ao corpo emana de outras esferas, tais como do

\footnotetext{
${ }^{7}$ Sem deter-me em cada uma dessas normas regulatórias, destaco as seguintes: art. 5ํ da Constituição Federal (Brasil, 1988); a parte que trata dos Direitos da Personalidade do Código Civil de 2002, artigos 2o, 6o, 11 ao 21, e ainda artigos 186 e 927 (Brasil, 2004); a Parte Especial do Código Penal de 1940, em seus artigos 121 ao 136 (Brasil, 1940); o Código de Ética Médica (CFM, 2009); as Resoluções do Conselho Federal de Medicina sobre a cirurgia de transgenitalismo (CFM, 2010), sobre as técnicas de reprodução assistida (CFM, 2013); sobre as pesquisas envolvendo seres humanos (CFM, 2012); a Declaração dos Direitos Humanos (ONU, 1948); a Declaração de Manzanillo (1996); a Declaração Universal do Genoma Humano e dos Direitos Humanos (UNESCO, 1997); e, finalmente, a Lei 9.434/1997, que trata da remoção de órgãos, tecidos e partes do corpo humano para fins de transplante e tratamento e dá outras providências (Brasil, 1997).
} 
Superior Tribunal Federal (STF) ou do Conselho Federal de Medicina (CFM). São exemplos a decisão do STF de 2008 (ADI 3510), estabelecendo que as pesquisas com células-tronco embrionárias não violam o direito à vida nem a dignidade da pessoa humana, quando analisou o artigo 5 o da Lei de Biossegurança (Lei 11.105/2005); e também a atual Resolução do CFM número 2.013/2013, que trata das técnicas de reprodução assistida, regulando os procedimentos relacionados com a gravidez por substituição.

Em resumo, o corpo moderno, em seu sentido legal, é um corpo que gira em torno de princípios constitucionais que se materializam em certas decisões judiciais superiores e de acordo com certos procedimentos médicos regulamentados. Mas o corpo, antes de se tornar lei, no sentido estrito, esconde um imenso campo de batalha no qual ciência, medicina, senso comum, valores morais seculares e religiosos se embatem.

\section{O corpo aos pedaços no processo legislativo}

Contar uma história social do corpo a partir do processo legislativo brasileiro - tal como o fez Mauss, em sua "história social" da pessoa, a partir de registros etnográficos diversos - assemelha-se muito ao esforço do jovem doutor Victor Frankenstein, descrito na obra clássica de Mary Shelley, de 1818, que concebe e dá vida a um monstro a partir da junção de pedaços de vários corpos (Shelley, 1997). A investigação da ordem pública do corpo por meio de projetos de lei apresentados na Câmara e no Senado revela seus fragmentos, partes, usos e componentes. São inúmeras as propostas acerca da doação de sangue, da doação e transplante de órgãos, de forma genérica, ou específica, quando trata de córneas, rins, fígado, pulmões etc., da utilização de próteses, da pesquisa com embriões e células-tronco, da reprodução assistida, do aborto ou da interrupção voluntária da gravidez, da eutanásia, da regularização dos enterramentos e cremação de cadáveres, entre outras.

A análise apresentada a seguir deriva de uma pesquisa mais abrangente da qual foram selecionados intencionalmente alguns casos particulares que colocam em perspectiva, às vezes de forma divergente, o estatuto do 
corpo $^{8}$. Para analisar alguns dos elementos desse conjunto, não optei por um recorte cronológico nem pela seleção de períodos legislativos. Trata-se de um ensaio analítico que ilustra o que foi discutido até o momento, com o objetivo de demonstrar o potencial de investigações acerca da ordem pública do corpo humano. Para tanto, fiz a seleção de projetos de lei de diferentes anos, e sobre diferentes temas, considerando as proposições em seu inteiro teor, isto é, a proposta de lei e sua justificação, sem esmiuçar sua tramitação, a partir do site da Câmara dos Deputados (https://www. camara.leg.br), na seção exclusiva para pesquisa da atividade legislativa, tendo como ponto de partida o fim do Estado Novo (1937-1946). Para tanto, foram utilizados os seguintes termos de busca: "sangue"; "doação de órgãos"; "aborto"; "interrupção da gravidez"; "eutanásia" e "ortotanásia".

\section{Venda ou doação de sangue}

Segundo Baud (1993, p. 213), as transfusões sanguíneas "inauguram a distribuição industrial dos produtos do corpo humano". No Brasil, os primeiros passos nesse sentido foram dados em 16 de maio de 1949, quando o deputado federal pernambucano Lima Cavalcanti, da União Democrática Nacional (UDN), propôs o Projeto de Lei 216/1949, que instituía providências de estímulo aos bancos de sangue no Brasil. Entre elas, estava consignar com louvor "a folha de serviço de militar, de funcionário público civil ou de servidor de autarquia, a doação voluntária de sangue, feita a Banco mantido por organismo de serviço estatal ou paraestatal, devidamente comprovada por atestado oficial da instituição" (Brasil, 1949). Além dessa menção, esses profissionais estavam dispensados do ponto no dia da doação.

Lima Cavalcanti menciona a "experiência da última Guerra", durante a qual os bancos de sangue foram fundamentais para o salvamento de vidas. Também cita a "constituição de um patrimônio comum a toda coletividade"

\footnotetext{
${ }^{8}$ Pesquisa pós-doutoral realizada na Université de Strasbourg, de 2018 a 2019, sob a supervisão de David Le Breton, intitulada Frontières sensibles: une étude des corps dans les limites de la législation brésilienne. Durante esse período, foi organizado um banco de dados contendo centenas de projetos de lei que dizem respeito ao corpo humano, abrangendo os anos de 1946 a 2019. Os resultados aqui apresentados são parciais e fazem parte do desdobramento da pesquisa que os originou.
} 
devido à escassez do fluido. Tratava-se, nas palavras do deputado, de um "dom de indivíduo a indivíduo" (Brasil, 1949). O projeto, que seguiu para a Comissão de Serviço Público Civil, recebeu parecer favorável, o qual destacava a "tragédia de Gericino", na qual morreram dez militares e outros quarenta ficaram feridos durante um exercício de combate (Explosão, 1949), sendo alguns deles salvos por meio da transfusão sanguínea de voluntários sensibilizados com o acidente. A proposta foi aprovada e tornou-se a Lei no 1.075 , de 27 de março de 1950, a qual, por sua vez, possibilitou a criação da Política Nacional do Sangue, regulamentada pela Lei 4.701, de 28 de junho de 1965.

O que hoje nos parece usual, a doação de sangue, na década de 1940 tratava-se prática incomum, pois este fluido corporal podia ser comercializado. Vendia-se sangue como uma mercadoria. No país, havia clínicas especializadas em armazenamento de sangue, as quais faziam parte de uma rede comercial privada, sem regulamentação estatal específica. As razões que levaram à mudança do estatuto legal do sangue de produto comercializável a um bem fora do comércio são inúmeras. Destacam-se, à época, além da tragédia de Gericino, medidas de higiene e saúde pública, pois a doação de sangue fazia das pessoas socialmente vulneráveis, mais suscetíveis a doenças infectocontagiosas, um grupo que a utilizava como forma de remuneração. Contudo, o sangue deixou de ser vendido por doadores somente na década de 1980 (Guerra, 2005).

\section{Doação voluntária ou compulsória de órgãos}

A história legislativa da doação e transplante de órgãos remonta, na Câmara dos Deputados, à proposição do deputado federal Adylio Martins Vianna, do Partido Trabalhista Brasileiro (PTB/RS), em 22 de agosto de 1958, quando apresentou o Projeto de Lei 4542/1958, que dispunha sobre "a extirpação de órgãos ou tecido de pessoa falecida". Seu projeto tornou-se a Lei 4280/1963, cujo art. 1으 estabelecia:

É permitida a extirpação de partes de cadáver, para fins de transplante, desde que o de cujus tenha deixado autorização escrita ou que não haja oposição por parte do cônjuge ou dos parentes até o segundo grau, ou de corporações religiosas ou civis responsáveis pelo destino dos despojos (Brasil, 1963). 
Em sua justificação, o deputado sublinha que "[a] técnica do enxerto em elemento humano constitui, inegavelmente, importante progresso na cirurgia moderna. Infelizmente, enfrenta sérias dificuldades no campo jurídico e muitas incompreensões de ordem moral" (Brasil, 1963). Durante e, principalmente, após a Segunda Guerra Mundial, a Medicina passou a desenvolver técnicas inovadoras de transplantação de órgãos e partes do corpo, o que não passou desapercebido dos legisladores brasileiros. Os transplantes de córnea tornaram-se comuns na década de 1950 nos Estados Unidos, Inglaterra, França, Espanha e na Itália, onde foi necessária uma aprovação da Igreja Católica. No Brasil, por exemplo, havia sido constituído o Banco de Olhos na cidade de Porto Alegre. A proposta do deputado federal Adylio Martins Vianna fora apresentada dez anos antes do primeiro transplante de coração no Brasil, em 22 de maio de 1968. Nesse contexto, a Medicina já desafiava o Direito, colocando-lhe novos limites no que diz respeito ao estatuto do corpo humano.

Segundo o Registro Brasileiro de Transplantes (ABTO, 2018), o número de transplantes realizados está aquém da necessidade, verificando-se uma lenta evolução de doadores efetivos no país, entre os anos de 2011 e 2018, ainda insuficiente para atender a demanda. Esse déficit serve de mote para a proposição de leis que promovem a doação de órgãos, por meio do registro de potenciais doadores, regulação de procedimentos médicos, financiamento da saúde etc. Mas também origina propostas que ultrapassam os limites constitucionais, impondo uma ruptura entre as noções de pessoa e corpo, tal como vimos no início deste artigo com o Projeto de Lei do deputado federal Francisco Silva acerca da "doação compulsória de órgãos", expressão que contém em si um contrassenso: legalmente, o ato de doar é voluntário e livre de qualquer obrigação.

Nesse mesmo sentido, existem três proposições já arquivadas por inconstitucionalidade na Câmara. A do deputado Irapuã Teixeira (PP/SP), que "[d]isciplina a pena física nos casos que especifica, instituindo a doação compulsória de órgãos", de 24 de junho de 2004 (Projeto de lei 3857/2004); e duas do deputado Daniel Silveira (PSL/RJ). A primeira delas estabelece "a cessão compulsória de órgãos e tecidos, células e partes do corpo humano para transplante ou enxerto, oriundos de agente que em prática de conduta 
delituosa em confronto com agentes públicos de segurança tenha como resultado final a morte encefálica", de 13 de fevereiro de 2019 (Projeto de lei 727/2019); e a segunda a "cessão compulsória de órgãos, no caso em que o cadáver apresenta indícios de morte por resultado de ação criminosa", de 13 de fevereiro de 2019 (Projeto de lei 729/2019). Tais projetos ferem os princípios assegurados constitucionalmente de dignidade da pessoa humana, da inviolabilidade do corpo e da autonomia e consentimento (Brasil, 2004; 2019a; 2019b).

\section{Barriga de aluguel ou gravidez por substituição}

Em 20 de agosto de 1990, estreava a novela Barriga de aluguel na emissora de televisão Rede Globo. A trama, escrita por Glória Perez, contava a história da jovem Clara, que "aluga" seu útero para o casal Ana e Zeca. De um lado, uma mulher pobre que "vende parte do seu corpo por tempo determinado" para ganhar dinheiro; de outro, um casal rico, sem condições de se reproduzir, que recorre ao serviço por intermédio de uma clínica especializada em reprodução assistida. Assim, estavam dados os elementos do drama que jogava com as crenças, moral e valores dos expectadores, misturando ciência, religião e costumes para questionar um dado incontornável da realidade desde Louise Brown, inglesa que nasceu em 1978, mais conhecida como o "bebê de proveta".

A novela teve duração de 243 capítulos e terminou em 1o de junho de 1991. Nesse mesmo ano, surgiram três projetos de lei sobre o tema na Câmara dos Deputados. O primeiro deles, de natureza proibicionista, é de autoria do deputado Maurici Mariano, do Partido da Reconstrução Nacional (PRN/SP). Em seu Projeto de Lei 809/1991, lê-se que "tem havido uma expansão alarmante das 'Mães de Aluguel' que, sem o menor pudor, se expõem até em anúncios classificados, oferecendo seus corpos por preços determinados". Ingressando no terreno que separa as pessoas das coisas, ainda afirma: "[n]ão resta dúvida que o óvulo é uma substância humana, e o embrião é o próprio homem em substância". Para embasar seus argumentos, cita a pesquisa feita pelo jornal Folha de S. Paulo, em 13 de julho de 1987, dizendo que a maioria dos brasileiros desaprova o procedimento, além de mencionar o posicionamento contrário da Confederação Nacional dos 
Bispos do Brasil (CNBB) a esse respeito; nas palavras de Dom Luciano, seu presidente, "a vida humana e a pessoa humana nunca podem ser colocadas em termo [sic] de mercado" (Brasil, 1991a).

O segundo Projeto de Lei, PL 1645/1991, apresentado por Nelson Gibson, do Partido do Movimento Democrático Brasileiro (PMDB/PE), é simples em sua argumentação. Proíbe o "ventre de aluguel", pois "[a] maternidade é a realização da mulher. É divina e deve merecer, dos poderes públicos, a mais ampla proteção" (Brasil, 1991c). Finalmente, o terceiro Projeto de Lei, PL 1737/1991, cujo autor é Osmânio Pereira, do Partido da Social Democracia Brasileira (PSDB/MG), é mais abrangente: estabelece, em seu art. 1ํ, que "[d]iante da lei, todo ser humano é uma pessoa, desde a fecundação até a morte" e também que "[t]oda ação, biológica ou médica não é lícita senão com a finalidade direta ou indireta, de proteger ou de restabelecer a saúde da pessoa" (Brasil, 1991d). A justificação do deputado reporta-se ao perigo da manipulação genética e aos avanços da ciência que ameaçam a "espécie humana", dizendo-se contrário a qualquer tipo de técnica que se vale do embrião, seja para fins científicos, seja para a procriação.

Atualmente, a expressão "gravidez por substituição" tem sido utilizada no lugar de "barriga de aluguel" ou "ventre de aluguel". Numa espécie de eufemismo, ao invés de "aluguel", utiliza-se "substituição" para contornar a ideia de que uma parte do corpo pode ser comercializada, o que constitui prática proibida no Brasil.

Para além da evidência dos efeitos que a indústria do entretenimento pode provocar na vida política nacional, o tema "barriga de aluguel" reflete uma preocupação com os avanços da ciência que dão ao corpo humano uma destinação que foge dos parâmetros anteriormente conhecidos e tidos como "naturais" quando se trata da reprodução. Esse "novo" corpo feminino - e atualmente já se fala na gestação por homens - altera radicalmente o estatuto do corpo em nossa legislação. O direito oferece respostas precárias para questões tais como: qual é o status civil da criança gerada por uma mulher com embrião implantado e oriundo de material genético de outrem? Essa criança tem o direito de saber quem a gerou? Quais os deveres e direitos das pessoas implicadas no processo? O que acontece se a mulher que 
ofereceu seu útero recusar-se a "entregar" o bebê para os pais genéticos? Eventualmente, se a gravidez for interrompida, quais são as consequências jurídicas?

Sobre o assunto, Luna (2002) trata da separação entre a "maternidade genética" e a "maternidade gestacional" como um interessante fenômeno para se estudar as práticas sociais no que diz respeito às noções de "natureza" e "cultura". Para antropóloga,

no contexto brasileiro a gestação ainda tem bastante peso para definir a maternidade, o que se percebe na resistência à prática de maternidade substituta. A doação de óvulos parece ter se tornado uma prática relativamente comum nas grandes clínicas de reprodução humana em contraste com a substituição. Haveria dois pontos para essa rejeição. Um deles é a construção no sistema de parentesco ocidental da maternidade como fato natural, na percepção de que a relação mãe-filho em si estaria no âmbito natural, sendo necessária a existência do pai ou marido para implantar a socialidade. A concepção da maternidade natural estaria presente tanto no discurso jurídico na definição da mãe pelo parto, como na ideia de uma natureza feminina centrada na reprodução e manifesta no instinto materno, conforme construído pela medicina dos séculos XVIII e XIX. O segundo ponto diz respeito a representações de gênero ocidentais correntes em que a mulher enquanto mãe é símbolo de abnegação, dotadas de um matiz peculiar no caso brasileiro (Luna, 2002, p. 273-274).

Atualmente, o site da Câmara dos Deputados lista 33 propostas sobre o assunto. Apesar disso, hoje a "gravidez por substituição" é regulada pelo Conselho Federal de Medicina (Resolução no 2168, de 21 de setembro de 2017), estabelecendo que "[a] cedente temporária do útero deve pertencer à família de um dos parceiros em parentesco consanguíneo até o quarto grau (primeiro grau - mãe/filha; segundo grau - avó/irmã; terceiro grau - tia/ sobrinha; quarto grau - prima)" (CFM, 2017).

\section{Aborto ou interrupção voluntária da gravidez}

Outra forma para indagar-se a respeito do estatuto do corpo é comparando os diferentes tipos de propostas legislativas acerca do aborto no Brasil. A natureza do embrião tornou-se um problema legal a partir do 
momento em que a ciência ultrapassou os limites da reprodução humana natural, inaugurando a era das fertilizações in vitro. A vida, reproduzida em laboratório, já dispensava o corpo como seu "abrigo natural", isto é, a vida poderia ser gerada artificialmente "fora do corpo", a partir da manipulação do embrião, permitindo sua reprodução controlada, armazenamento, congelamento e, atualmente, até mesmo a clonagem.

Antes da era dos bebês de proveta, a viabilidade do nascituro já era um problema legislativo. Nosso Código Penal, em seu art. 128, vigente desde 1940, condena o aborto, abrindo exceção para dois casos excepcionais classificados como "aborto necessário", seja quando não há outro meio de salvar a vida da gestante, seja quando a gravidez resulta de estupro. Entretanto, tal artigo nunca foi tema pacífico e a história legislativa nos mostra proposições paradoxais a respeito do tema.

Um retorno ao passado nos mostra o quanto o estatuto do embrião alterou-se se confrontado com as proposições atuais. Como exemplo, cito o Projeto de Lei no 632, de 17 de maio de 1972, que inclui o "'aborto eugênico' ou 'profilático', como o denominam os médicos, entre os tipos de aborto não punidos pelo Código Penal Brasileiro". O autor do projeto, deputado José Guilherme de Araújo Jorge, do (MDB/RJ), para justificar sua proposição, cita a obra "Medicina Legal", do professor Hélio Gomes, que defende o aborto eugênico nos seguintes termos:

A interrupção propositada da prenhez toda vez que razões científicas autorizassem a suposição de que determinada gravidez ofereceria toda probabilidade (não a certeza, que esta não existe em medicina) de dar nascimento a um aleijado, tarado, deficiente mental. Alguns autores chamam também a este aborto de "profilático", porque evita o nascimento inconveniente. Um epilético procria com uma débil mental; um alcoólatra fecunda uma esquizofrênica; um maníaco viola uma histérica. Quais as "probabilidades biológicas sobre a saúde física, mental e moral da prole resultante desses cruzamentos? A pior e a mais antieconômica possível: uma criança cega, surda, deficiente mental, aleijada, custa três vezes mais ao Estado do que uma criança normal. Logo, seria preferível fazer abortar (o melhor seria impedir a gravidez pelo ensino e legalização da anticoncepção eugênica) do que ver nascer infelizes, condenados a uma vida cheia de sofrimentos, num mundo dominado pelo egoísmo e pela árdua luta pela existência (Helio Gomes, citado em Brasil, 1972). 
A questão da eugenia, consagrada por meio das teorias da degenerescência sustentadas por Nina Rodrigues até o início do século $X X$, ainda presentes no projeto de lei acima, subentende a viabilidade do nascituro, ou seja, as condições que o embrião reúne para desenvolver-se. Nesse caso, tal desenvolvimento seria limitado por taras, degenerescência, defeitos. Atualmente, discutida numa outra chave, a questão da viabilidade do nascituro está em pauta nas discussões sobre o "aborto necessário" presente na Ação Direta de Inconstitucionalidade (ADI) no 5581, de 5 de setembro de 2016, a qual trata da interrupção da gravidez nos casos de fetos com microcefalia decorrente da contaminação de gestantes pelo Zika vírus.

Nas discussões contemporâneas sobre o aborto, o que diferencia o Projeto de Lei no 632/1972 da ADI no 5581 é a atribuição de personalidade jurídica ao embrião. No primeiro caso, não há considerações a esse respeito. Em 1972, o aborto restringia-se a um problema de ordem legal tipificado pelo Código Penal. No segundo caso, a ordem legal penal e civil concorrem, borram os limites que distinguem as noções de pessoa e corpo, configurando exatamente o imbróglio jurídico em torno da questão.

Maria Isabel Baltar da Rocha (1996) fez um excelente mapeamento das propostas legislativas concernente ao aborto entre os anos de $1946 \mathrm{e}$ 1995. Nesse período, analisou 49 projetos de lei, em diferentes períodos legislativos, acompanhando os debates em torno do tema, os quais se acirraram a partir da redemocratização do país e consequente promulgação da Constituição Federal de 1988. Em termos gerais, seu artigo mostra que o aborto, no Parlamento, nasce como uma questão ligada ao Código Penal, sendo progressivamente associado a outras esferas legais e direitos, por exemplo, na área trabalhista e de saúde. Quanto aos atores envolvidos nas discussões, destaca a forte oposição da Igreja Católica às iniciativas progressistas que se apoiavam no direito de as mulheres decidirem a respeito dos seus próprios corpos. No final dos anos de 1990, entram em cena os representantes evangélicos, também contrários ao aborto, articulados em diferentes frentes que, contemporaneamente, sustentam novas estratégias para a criminalização e proibição da prática em qualquer circunstância.

Uma das formas de se alcançar o objetivo de proibir o aborto qualquer que seja a circunstância é atribuindo personalidade jurídica ao embrião, tal 
como o faz o Estatuto do Nascituro, Projeto de lei 6150/2005, de autoria dos deputados Osmânio Pereira (PTB-MG) e Elimar Máximo Damasceno (PRONA-SP). Nele, lê-se que "[n]ascituro é o ser humano concebido, mas ainda não nascido" e que "[o] conceito de nascituro inclui os seres humanos concebidos 'in vitro', os produzidos através de clonagem ou por outro meio científica e eticamente aceito" (Brasil, 2005) Esse projeto foi arquivado, mas deu origem a outra proposta, que se encontra em andamento, o Projeto de Lei 478/2007, que repete os mesmos termos do anterior. Outro exemplo de proposta que pretende proibir o aborto em qualquer fase da gestação está no Projeto de Lei no 10.774, de 3 de setembro de 2018, apresentado pelo deputado Marcos Reategui (PSD/AP), que altera o Código Civil para estabelecer como marco inicial da personalidade civil a concepção do embrião vivo.

Para circunscrevermos o debate jurídico em torno das posições "próvida", contrárias ao aborto, e das "pró-escolha", que tratam da interrupção voluntária da gravidez, não se pode perder de vista as bases moral, religiosa e filosófica que sustentam a controvérsia. Para Dworkin (2003), ela desdobrase em função do valor intrínseco que nós ocidentais atribuímos à vida, na acepção de objeto sagrado segundo a qual a concebemos, seja de ordem religiosa, quando a julgamos obra divina, seja no seu significado laico de coisa inviolável. Nesse sentido, sustenta-se a proibição ou legalização do aborto por meio de argumentos que o filósofo chama de "independentes", os quais seriam o ponto justo de discussão a partir do qual podem ser traçadas as decisões legais a respeito de uma prática que desafia a sacralidade da vida, ou seja, de seu valor em si. Entretanto, ao lado das "objeções independentes", existem as "objeções derivativas", isto é, aquelas que atribuem ao feto direitos e interesses próprios. Essas, em sua maioria, são aquelas invocadas nos projetos de lei atuais que procuram proibir o aborto, qualquer que seja a circunstância, atribuindo ao embrião personalidade jurídica. Defende-se, portanto, a vida em função de objetos que lhe são externos, por expectativas de direito.

Segundo Dworkin (2003, p. 1), tanto o aborto quanto a eutanásia são "práticas nas quais ocorre uma opção pela morte". No primeiro caso, a morte ocorreria "antes que a vida tenha começado". No segundo, quando 
a vida "efetivamente terminou". Ao colocar o problema nesses termos, o filósofo, obviamente, está atribuindo à vida um significado outro que não é contrário ao de morte. Além e independentemente desse significado, meu interesse recai sobre o que consideramos o substrato da vida, seu suporte, o qual materializa a controvérsia acerca do aborto, quando tratamos do embrião, ou da eutanásia quando se considera o corpo em estado vegetativo. Em ambos os casos, o estatuto jurídico do corpo é um dos elementos que definirá o conjunto de decisões legais atinentes aos procedimentos que Ihes são próprios ${ }^{9}$.

\section{Eutanásia, ortotanásia ou morte provocada}

Do grego, euthanasía quer dizer "morte sem sofrimento". Seu sentido também está relacionado com os significados de suicídio assistido, isto é, morte programada e assistida por outrem; ortotanásia, que significa "boa morte" ou "morte sem sofrimento"; e distanásia, significando "morte lenta" ou "morte com sofrimento". No âmbito legal, a eutanásia desafia os princípios da autonomia e da liberdade em relação ao próprio corpo e à vida, constituindo-se tema polêmico que confronta a medicina, a religião, a moral e os costumes da mesma forma que acontece quando se discute o aborto. Não há previsão legal para sua prática que, eventualmente, pode ser enquadrada nos artigos 121 §1, e 122 do Código Penal, segundo os quais "induzir alguém a suicidar-se ou prestar-lhe auxilio para que o faça" é passível de condenação (Brasil, 1940).

Dworkin (2003, p. 256-257), ao tratar da eutanásia, coloca uma questão fundamental: "[q]uando deveríamos pensar a respeito de quando e como morrer"? Para ele, tal decisão não envolve apenas questões religiosas, mas também políticas e jurídicas muito semelhantes àquelas que envolvem as discussões a respeito do aborto, mas de forma diferente.

\footnotetext{
${ }^{9}$ Embora a obra de Dworkin (2003) seja fundamental para a discussão dos fundamentos favoráveis e contrários ao aborto e à eutanásia, detenho-me sobre o estatuto legal do corpo sem aprofundar seus argumentos, os quais não tratam diretamente da questão aqui analisada.
} 
Um dos primeiros projetos de lei a respeito da eutanásia é de autoria do deputado Inocêncio Oliveira (PDS/PE). Sua proposta no 4662, de 11 de junho de 1981,

Permite ao médico assistente o desligamento dos aparelhos de um paciente em estado de coma terminal ou na omissão de um medicamento que irá prolongar inutilmente uma vida vegetativa, sem possibilidade de recuperar condições de vida sofrível, em comum acordo com os familiares e dá outras providências (Brasil, 1981).

Em sua justificação, o deputado evoca razões médicas, jurídicas e religiosas que configuram os debates em torno do tema nos países em que a eutanásia foi aprovada e, também, naqueles onde há propostas para sua institucionalização. O projeto de Oliveira não foi aprovado, mas durante sua tramitação causou repercussão nacional. Dezenas de municípios enviaram requerimentos para a Câmara de Deputados requerendo o arquivamento da proposta, expondo, principalmente, argumentos de ordem religiosa.

A decisão mais recente sobre o assunto diz respeito à regulamentação da ortotanásia em 8 de dezembro de 2010, que exige a autorização expressa do paciente ou de sua família para a prática e assegura todos os cuidados básicos e paliativos cabíveis. Trata-se de um substitutivo ao Projeto de Lei no 6715 de 2009, do Senado Federal, que descriminalizava a prática. Na Câmara Federal, nesse período, ainda tramitam três projetos de lei acerca do tema. Enquanto os Projetos de Lei 3002/2008 e 6544/2009 procuram regulamentar a ortotanásia no país, o Projeto de Lei 5008/2009 a proibia. De um lado, defende-se o direito de uma morte digna e respeito à autonomia do indivíduo. De outro, o direito à vida, fundado na crença religiosa de reabilitação do corpo cujas funções e viabilidade foram desacreditadas pela medicina.

\section{Epílogo: a moral da história no corpo}

Para finalizar este artigo, pontuo uma constatação que une os trabalhos de Labbée (1990), Baud (1993), Le Breton (1993) e Edelman (2009), aqui referenciados: o corpo é um símbolo e o respeitamos pelo significado que 
ele assume em nosso imaginário social e não por aquilo que ele é, em seu simples sentido orgânico, biológico, coisa afeita aos desígnios da Medicina.

Meu objetivo aqui foi apresentar um exercício de reflexão sobre o que chamei de ordem pública do corpo. Tomei como elementos de reflexão propostas legais que condensam costumes, valores religiosos, conhecimentos científicos, econômicos e legais. Por isso, escolhi temas controversos para mostrar o potencial de análises desse tipo.

Não é possível considerar a atual ordem pública do corpo e seu estatuto sem nos defrontarmos com suas fronteiras. A carga moral envolvida nas discussões a esse respeito levanta um de seus principais limites: a pessoa é o corpo; o corpo é a pessoa. Entretanto, quando o corpo é visto em suas partes, essa relação mostra-se ambígua, pessoa e corpo distanciam-se, revelando novas fronteiras que se mostram no confronto do Direito Civil com o Direito Penal, seja quando falamos de aborto, seja quando nos referimos à eutanásia e à ortotanásia. Entre o dom e a mercadoria, outro limite do corpo, entram as discussões a respeito da doação de sangue ou de órgãos e até mesmo a gravidez por substituição. Em defesa da autonomia do indivíduo e do direito à vida, levantam-se as questões em torno da interrupção voluntária da gravidez. Na lei, a noção de corpo é um elemento suspenso que às vezes oscila entre a noção de pessoa e a noção de coisa. Como Edelman (2009) diria, no título de seu trabalho, "nem coisa nem pessoa". Meu interesse é fazer desse dilema, ou dessas fronteiras, uma oportunidade de investigar a ordem pública do corpo no Brasil em diferentes contextos sociais e políticos.

Quanto ao poder analítico da utilização desses contextos como fonte de pesquisa, refiro-me ao texto de Joan Scott (1999), "O enigma da igualdade" (The conundrum of equality), no qual a historiadora analisa a tensão existente entre as ideias de igualdade e diferença, os direitos dos indivíduos e as identidades dos grupos. Segundo ela, não faz sentido questionar a proeminência dos direitos dos indivíduos sobre os direitos dos grupos ou vice-versa, porque são fenômenos históricos e contingentes. Em sua avaliação, é melhor questionar-se como o processo de diferenciação opera, a partir de propostas analíticas que tomam a igualdade e a identidade como efeitos do processo social e político e não como entidades eternas. 
Ao tomar o argumento de Scott como referência, não se pretende dar uma resposta sobre a proeminência do corpo sobre a pessoa, ou da pessoa sobre o corpo, no sentido legal do termo, mas sim conhecer os sentidos que o corpo assume em nossa sociedade, refletindo seus valores no ordenamento jurídico, sendo, em última análise, as leis tomadas como diretrizes que regem a vida social. Dessa forma, o processo legislativo nos oferece um rico campo de debates sobre o corpo, permitindo um conhecimento sociológico sobre temas que estão sendo constantemente discutidos quando falamos sobre nós mesmos e nossas vidas.

Alexandre Zarias é Doutor em Sociologia, professor e pesquisador da Fundação Joaquim Nabuco (Fundaj), Recife, Pernambuco.

$\equiv$ alexandre.zarias@fundaj.gov.br.

\section{Referências}

1. ABTO. Associação Brasileira de Transplante de Órgãos. Registro Brasileiro de Transplantes. Ano XXIV, n. 4, 2018.

2. AUTOS de Devassa da Inconfidência Mineira. Mandado para execução da pena de morte contra José Joaquim da Silva Xavier [21 de abril de 1792]. Belo Horizonte: Câmara dos Deputados; Imprensa Oficial de Minas Gerais, v. 7, 1982.

3. BAUD, Jean-Pierre. L'affaire de la main volée. Une histoire juridique du corps. Paris: Seuil, 1993.

4. BRASIL. Câmara dos Deputados. Projeto de Lei n. 216. Dá providência de estímulo aos Bancos de Sangue. Rio de Janeiro, 16 de maio de 1949.

5. BRASIL. Câmara dos Deputados. Projeto de Lei n. 632. Inclui o "aborto eugênico" no Art. 128 do Código Penal Brasileiro. Brasília, 17 de maio de 1972.

6. BRASIL. Câmara dos Deputados. Projeto de Lei n. 4662. Permite ao médico assistente o desligamento dos aparelhos de um paciente em estado de coma terminal [...]. Brasília, 26 de maio de 1981.

7. BRASIL. Câmara dos Deputados. Projeto de Lei n. 809. Dispõe sobre a proibição do implante de embrião em mulher que não seja a própria geradora e dá outras providências. Brasília, 17 de maio de 1991a.

8. BRASIL. Câmara dos Deputados. Projeto de Lei n.1471. Determina a doação de órgãos, tais como coração, pulmões, rins, olhos e outros, por criminosos condenados [...]. Brasília, 13 de setembro de 1991b. 
9. BRASIL. Câmara dos Deputados. Projeto de Lei n.1645. Tipifica como crime a cessão de útero para fins de inseminação artificial. Brasília, 17 de setembro de 1991c.

10. BRASIL. Câmara dos Deputados. Projeto de Lei n. 1737. Dispõe sobre informações genéticas, doação de órgãos humanos e dá outras providências. Brasília, 11 de novembro de 1991d.

11. BRASIL. Câmara dos Deputados. Projeto de Lei n. 3857. Disciplina a pena física nos casos que especifica, instituindo a doação compulsória de órgãos. Brasília, 24 de junho de 2004.

12. BRASIL. Câmara dos Deputados. Projeto de Lei n. 6150. Dispõe sobre o Estatuto do Nascituro e dá outras providências. Brasília, 1 de novembro de 2005.

13. BRASIL. Câmara dos Deputados. Projeto de Lei n. 727. Estabelece a cessão compulsória de órgãos e tecidos, células e partes do corpo humano para transplante ou enxerto, oriundos de agente que em prática de conduta delituosa em confronto com agentes públicos de segurança tenha como resultado final a morte encefálica. Brasília, 13 de fevereiro de 2019a.

14. BRASIL. Câmara dos Deputados. Projeto de Lei n. 729. Disciplina a cessão compulsória de órgãos, no caso em que o cadáver apresenta indícios de morte por resultado de ação criminosa. Brasília, 13 de fevereiro de $2019 \mathrm{~b}$.

15. BRASIL. Presidência da República. Código civil brasileiro. São Paulo: Revista dos Tribunais, 2004.

16. BRASIL. Presidência da República. Constituição da República Federativa do Brasil. Brasília, 5 de outubro de 1988.

17. BRASIL. Presidência da República. Lei n. 2.848, de 07 de dezembro de 1940. Código Penal. Rio de Janeiro, 7 de dezembro de 1940.

18. BRASIL. Presidência da República. Lei n. 4280. Dispõe sobre a extirpação de órgão ou tecido de pessoa falecida. Brasília, 6 de novembro de 1963.

19. BRASIL. Supremo Tribunal Federal. Arguição de Descumprimento de Preceito Fundamental n. 54/DF - Distrito Federal. Relator: Ministro Marco Aurélio. Pesquisa de Jurisprudência, Acórdãos, 12 de abril 2012. Disponível em: < http:// portal.stf.jus.br/processos/detalhe.asp?incidente $=2226954>$.

20. BRASIL. Supremo Tribunal Federal. Ação Direta de Inconstitucionalidade n. 5581/DF - Distrito Federal. Relatora: Ministra Cármen Lúcia. Pesquisa de Jurisprudência, Petição Inicial, 24 de agosto de 2016a. Disponível em: < http:// portal.stf.jus.br/processos/detalhe.asp?incidente $=5037704>$.

21. BRASIL. Supremo Tribunal Federal. Habeas corpus n. 124.306/DF - Distrito Federal. Redator: Ministro Luís Roberto Barroso, Brasília., Acórdãos, 29 de novembro de 2016b. Disponível em: < http://portal.stf.jus.br/processos/detalhe. asp? incidente $=4637878>$.

22. BRAUNER, Maria-Claudia C.; LOBATO, Anderson C. Le corps humain en droit brésilien: une protection qui cherche à concilier la dignité humaine et I'autonomie corporelle. LIGER-FEUILLET, Brigitte; SCHAMPS, Geneviève. 
Principes de protection du corps et biomédecine. Collection Droit, Bioéthique et Société. Bruxelles: Bruylant, 2015 p. 333-344.

23. CARVALHO, José Murilo de. A formação das almas: o imaginário da República no Brasil. São Paulo: Companhia das Letras, 1995.

24. CHAUVENETT, Antoinette. A lei e o corpo. Physis, Rio de Janeiro, v. 15, supl. p. 17-56, 2005.

25. CONSELHO Federal de Medicina. Resolução n. 2168. Adota as normas éticas para a utilização das técnicas de reprodução assistida [...]. Brasília, 21 de setembro de 2017.

26. CONSELHO Federal de Medicina. Resolução n. 1931. Aprova o Código de Ética Médica. Brasília, 17 de setembro de 2009.

27. CONSELHO Federal de Medicina. Resolução n. 1955. Dispõe sobre a cirurgia de transgenitalismo e revoga a Resolução CFM no 1.652/02. Brasília, 12 de agosto de 2010.

28. CONSELHO Federal de Medicina. Resolução n. 466. Aprova as diretrizes e normas regulamentadoras de pesquisas envolvendo seres humanos. Brasília, 12 de dezembro de 2012.

29. CONSELHO Federal de Medicina. Resolução n. 2013. Adota as normas éticas para a utilização das técnicas de reprodução assistida, anexas à presente resolução, como dispositivo deontológico a ser seguido pelos médicos e revoga a Resolução CFM no 1.957/10. Brasília, 16 de abril de 2013.

30. DECLARAÇÃO Ibero-Latino-Americana sobre Ética e Genética. Adotada durante o Encontro sobre Bioética e Genética de Manzanillo, México, 1996.

31. DWORKIN, Ronald. Domínio da vida: aborto, eutanásia e liberdades individuais. São Paulo: Editora Martins Fontes; 2003.

32. EDELMAN, Bernard. Ni chose ni personne. Le corps humain en question. Paris: Hermann, 2009.

33. EXPLOSÃO em Gericinó. A Noite. Rio de Janeiro, 24 de maio de 1949, p. 10-11.

34. GUERRA, Celso C. C. Fim da doação remunerada de sangue no Brasil faz 25 anos. Rev. Bras. Hematol. Hemoter., v. 27, n. 1, p. 1-3, mar. 2005.

35. LABBÉE, Xavier. Condition juridique du corps humain. Avant la naissance et après la morte. Lille: Presses Universitaires de Lille, 1990.

36. LE BRETON, David. La sociologie du corps. Paris: PUF, 1992.

37. LE BRETON, David. La chair à vif: usage médicaux et mondains du corps humain. Paris: Métailié, 1993.

38. LE BRETON, David. L’adieu au corps. Paris: Métailié, 1998.

39. LE BRETON, David. Corps et personne: quelle(s) anthropologie(s) pour le droit? LIGER-FEUILLET, Brigitte; SCHAMPS, Geneviève. Principes de protection 
du corps et biomédecine. Collection Droit, Bioéthique et Société. Bruxelles: Bruylant, 2015, p. 11-22.

40. LE BRETON, David. Patrimonialité du corps: un approche anthropologique. LIGER-FEUILLET, Brigitte; OKTAY-OZDEMIR, Saibe. La non-patrimonialité du corps huma du principe à la réalité. Collection Droit, Bioéthique et Société. Bruxelles: Bruylant, 2017, p. 351-363.

41. LUNA, Naara. Maternidade desnaturada: uma análise da barriga de aluguel e da doação de óvulos. Cad. Pagu, Campinas, n. 19, p. 233-278, 2002. doi: 10.1590/So104-83332002000200010

42. MAUSS, Marcel. As técnicas do corpo. MAUSS, Marcel. Sociologia e antropologia. São Paulo: Cosac Naify, [1934] 2003a.

43. MAUSS, Marcel. Uma categoria do espírito humano: a noção de pessoa, a de "Eu" [1938]. MAUSS, Marcel. Sociologia e antropologia. São Paulo: Cosac Naify, 2003b.

44. ONU - Organização das Nações Unidas. Declaração Universal dos Direitos Humanos, 1948.

45. PEREIRA, Caio M. da S. Instituições de Direito Civil. v. 1, Rio de Janeiro: Forense, 1994.

46. ROCHA, Maria Isabel B. da. A questão do aborto no Brasil: o debate no Congresso. Rev. Estud. Fem., Florianópolis, ano 4, n. 2, p. 381-398, 1996.

47. SCOTT, Joan. The conundrum of equality. Occasional papers of the School of Social Science. Paper number 2, Princeton, march 1999.

48. SHELEY, Mary. Frankenstein. Porto Alegre: L\&PM, 1997.

49. SILVA, De Plácido E. Vocabulário jurídico. Rio de Janeiro: Forense, 2005.

50. UNESCO - United Nations Educational, Scientific and Cultural Organization. Declaração Universal do Genoma Humano e dos Direitos Humanos. Adotada pela Conferência Geral da UNESCO, em sua 29 sessão, 1997. 